\title{
Tatalaksana Henti Jantung di Lapangan Permainan
}

\author{
Putra Rizki, ${ }^{1}$ Nani Cahyani ${ }^{2,3}$ \\ ${ }^{1}$ Program Studi Ilmu Kedokteran Olahraga, Fakultas Kedokteran Universitas Indonesia \\ ${ }^{2}$ Divisi Kedokteran Olahraga, Fakultas Kedokteran Universitas Indonesia \\ ${ }^{3}$ Center For Sports and Exercise Studies, IMERI, Fakultas Kedokteran Universitas Indonesia \\ E-mail: dr_putrarizki@yahoo.com
}

\begin{abstract}
Cardiac arrest is the most common cause of sudden death in athletes on the field of play. There are reports of cardiac arrest in athletes 1: 4000 to 1: 8000.Cardiac and noncardiac causes have been implicated as a causes of death in the field of play. PreParticipation Evaluation (PPE) has been recommended for primary prevention of cardiac arrest in athletes due to cardiac problems. Prevention of sudden cardiac death on the field of the play should be done by immediate, precise and correct treatment. Immediate, precise and correct treatment can be provided if medical management is well performed before and during the event. Medical management in sudden cardiac arrest treatment on the field of play consists of early preparation, emergency action plan, preparing equipment, personnel, training, communication, transportation and final preparation. An ideal treatment includes elements of the chain of survival from sudden cardiac arrest.
\end{abstract}

Keywords: sudden cardiac arrest, field of play, medical management, SCA treatment

\begin{abstract}
ABSTRAK
Henti jantung adalah penyebab kematian mendadak terbanyak pada atlet di lapangan permainan. Terdapat laporan kejadian henti jantung pada atlet 1:4000 sampai 1:8000. Penyebab kematian akibat henti jantung di lapangan permainan bisa karena masalah jantung dan masalah selain jantung. Untuk pencegahan primer terjadinya henti jantung pada atlet di lapangan permainan yang disebabkan masalah jantung direkomendasikan melakukan PreParticipation Evaluation (PPE). Untuk pencegahan terjadinya kematian akibat henti jantung di lapangan permainan harus dilakukan tatalaksana yang cepat, tepat dan benar. Tatalaksana yang cepat, tepat dan benar dapat diberikan jika manajemen medis dilakukan dengan baik sebelum dan saat event berlangsung. Manajemen medis dalam tatalaksana henti jantung di lapangan permainan terdiri dari persiapan awal, rencana kegawatdaruratan, mempersiapkan peralatan, personel, pelatihan, komunikasi, transportasi dan persiapan akhir. Tatalaksana di lapangan permainan yang ideal mencakup elemen rantai keselamatan pada henti jantung.
\end{abstract}

Kata kunci: henti jantung, lapangan permainan, manajemen medis, penanganan SCA

\section{PENDAHULUAN}

Henti jantung adalah hilangnya

fungsi pompa jantung secara mendadak, terjadi tiba-tiba, dipicu oleh kerusakan listrik pada jantung yang menyebabkan detak jantung tidak teratur (aritmia) dan selanjutnya akan menyebabkan gangguan pompa jantung, sehingga jantung tidak 
bisa memompa darah ke otak, paru-paru dan organ lainnya (Hazinski et al., 2015). Henti jantung merupakan penyebab kematian terbanyak pada atlet di lapangan permainan. Di Amerika terdapat satu kejadian henti jantung setiap tiga hari pada atlet. Angka keselamatan kejadian henti jantung di lapangan permainan tercatat meningkat karena pemberian RJP dan aplikasi automated external defibrilator (AED) segera setelah kejadian (Toresdahl, Courson, Börjesson, Sharma, \& Drezner, 2012).

Penyedia layanan kesehatan pada event olahraga diharapkan mampu menangani kegawatdaruratan jantung di lapangan dengan cepat, tepat dan benar. Untuk menghasilkan tanggap darurat yang terkoordinasi dan efisien pelayanan kesehatan dalam suatu event harus menyediakan perencanaan darurat yang jelas, tenaga terlatih dalam resusitasi jantung paru (RJP) dan dalam menggunakan automated external defibrilator (AED), akses yang baik dalam menggunakan alat-alat kegawatdaruratan serta koordinasi yang baik dalam komuni- kasi dan sistem transportasi. Persiapan yang baik berperan meningkatkan angka kelangsungan hidup seorang atlet, sehingga dibutuhkanlah pengetahuan yang baik sejak persiapan awal dalam tatalaksana henti jantung di lapangan permainan (McDonagh \& Zideman, 2015; Toresdahl et al., 2012).

\section{Insiden kematian henti jantung pada} atlet

Berdasarkan pedoman kardiovaskular pada atlet yang dikeluarkan Komite Olimpiade Internasional (IOC) saat ini terdapat 15 studi insiden kematian akibat henti jantung pada atlet, enam studi pada populasi atlet umum (usia 8-44), empat studi pada atlet mahasiswa (usia 1824) dan enam studi pada atlet sekolah (usia 14-18). Dari enam studi pada populasi atlet umum tiga studi menyatakan insiden pada populasi atlet umum diperkirakan 1 dari 82.645 sampai 1 dari 300.000 atlet per tahun, tiga studi lain mempunyai estimasi kejadian henti jantung pada populasi atlet umum 1 dari 37.593 sampai 1 dari 163.934 
atlet dalam setahun. Pada atlet mahasiswa perkiraan insiden henti jantung sebesar 1 dari 43.770 sampai 1 dari 67.000 atlet dalam setahun. Pada atlet sekolah insiden diperkirakan 1 dari 87.719 atlet per tahun (Wilson \& Drezner, 2016).

Peneliti lain Harmon dkk mengumpulkan 13 studi tentang insiden kematian akibat henti jantung pada atlet. Penelitian ini mengelompokkan insiden berdasarkan insiden pada atlet mahasiswa dan insiden pada atlet sekolah. Perkiraan insiden pada atlet mahasiswa sekitar 1 dari 50.000 atlet per tahun. Sedangkan perkiraan insiden pada atlet siwa antara 1 dari 50.000 sampai 1 dari 80.000 atlet per tahun (Harmon et al., 2015).

\section{Etiologi henti jantung pada atlet}

Berdasarkan hasil otopsi pada atlet yang mengalami kematian akibat henti jantung, penyebab kematian terbanyak pada atlet di Amerika dan Eropa berbeda. Hasil otopsi di Eropa yang paling banyak muncul sebagai penyebab kematian adalah autopsy negative-sudden unexplained death (AN-SUD). Penyebab kematian di Amerika terbanyak yang ditemukan pada henti jantung adalah hypertrophic cardiomiopathy (HCM). Sampai saat ini berdasarkan hasil penelitian yang ada, masih terus disarankan untuk dilakukan pengembangan secara forensik dan otopsi molekular untuk menemukan ketepatan dalam penentuan penyebab kematian akibat henti jantung pada atlet (Harmon, Drezner, Wilson, \& Sharma, 2014).

Pengelompokan penyebab kematian berikutnya berdasarkan usia. Harmon dkk mengelompokkan etiologi tersebut pada atlet usia >35 tahun dan atlet usia $<35$ tahun. Pada atlet usia >35 tahun penyebab kematian lebih berhubungan pada komplikasi dari penyakit jantung koroner (karena aterosklerosis). Pada atlet usia $<35$ tahun penyebab kematian akibat henti jantung berhubungan dengan kelainan kongenital pada jantung. Penyebab henti jantung pada atlet usia $<35$ tahun di antaranya adalah hypertrophic cardiomiopathy/HCM (36\%), coronary artery anomalies (16\%) 
sisanya diikuti oleh arythmogenic right

ventricular cardiomyopathy (ARCV),

Marfan syndrom, long QT syndrome,

Brugada syndrome, Cathecolamine

familial tachycardia (Harmon et al., 2015).

\section{Faktor risiko henti jantung atlet}

Dari data insiden kematian henti jantung pada atlet, Wafsy dkk menganalisa risiko relatif dan mendapatkan kesimpulan, untuk faktor risiko jenis kelamin atlet laki-laki (1/37.790) punya risiko lebih tinggi mengalami henti jantung di lapangan dibandingkan atlet perempuan (1/121.593). Untuk faktor risiko ras, ras kulit hitam (1/21.491) mempunyai risiko yang lebih tinggi terjadinya henti jantung di lapangan dibandingkan ras kulit putih (1/68.354). Untuk jenis olah raga, bola basket (1/8.978) menduduki risiko tertinggi untuk terjadinya henti jantung di lapangan diikuti soccer (1/23.689) dan football (1/35.951) (Wafsy \& Hutter, 2016).

Pencegahan terjadinya henti jantung pada atlet
American Heart Association

(AHA) dan Europian Society of Cardio$\operatorname{logy}$ (ESC) setuju untuk melakukan screening PPE (pre-participation evaluation) terutama sistem kardiovaskular pada atlet untuk alasan medis, etika dan hukum. IOC menetapkan PPE sebagai pencegahan primer terjadinya henti jantung di lapangan permainan. PPE pada umumnya terdiri dari anamnesis riwayat penyakit dahulu dan keluarga, pemeriksaan fisik, EKG 12 lead, dan pemeriksaan lain yang dirasa perlu oleh dokter pemeriksa. PPE sangat penting, karena dapat mendeteksi berbagai kelainan pada jantung seperti hipertrofi, kelainan irama, kelainan katup, kelainan pembuluh darah, dan kelainan jantung kongenital (Wilson \& Drezner, 2016).

\section{Manajemen medis tatalaksana henti} jantung

Tatalaksana henti jantung yang cepat, tepat dan benar merupakan pencegahan terjadinya kematian akibat henti jantung di lapangan permainan. Tatalaksana tersebut dapat diberikan jika perenca- 
naan kegawatdaruratan dilakukan dengan benar. Manajemen medis yang baik berperan penting dalam mempersiapkan pelayanan kegawatdaruratan tersebut. Komponen yang perlu diperhatikan dalam manajemen medis tatalaksana henti jantung antara lain persiapan awal, perencanaan kegawatdaruratan, peralatan, personel, pelatihan, komunikasi, transportasi dan persiapan akhir (McDonagh \& Zideman, 2015; Wilson \& Drezner, 2016).

\section{Persiapan awal}

Petugas kesehatan yang bertanggung jawab pada event harus mengetahui ketua penyelenggara event serta struktural lengkap dalam event tersebut, untuk mendapatkan dokumen dan data yang berguna untuk perencanaan kegawatdaruratan saat event berlangsung. Dokumen dan data yang diperlukan antara lain tempat penyelenggaraan, jumlah atlet dan perkiraan penonton event saat ini, PPE dari atlet, berbagai dokumentasi event sebelumnya (jika event tersebut merupakan event rutin/ tahunan) yang dirasa perlu untuk pela- yanan kedaruratan jantung event saat ini. Dengan ketersediaan dokumen dan data tersebut petugas kesehatan mampu memetakan alur masuknya tenaga medis, evakuasi dan rujukan serta menilai faktor risiko kejadian henti jantung yang mungkin terjadi di lapangan permainan (McDonagh \& Zideman, 2015).

\section{Perencanaan kegawatdaruratan}

Perencanaan kegawatdaruratan jantung merupakan bagian yang sangat penting dan kritis dalam suatu event olahraga. Perencanaan kegawatdaruratan harus memiliki protokol, prosedur dan aturan yang jelas. Rencana harus berdasarkan kepada kontribusi dan konsesus badan terkait, dan harus dikomunikasikan kepada semua pihak terkait (mulai panitia penyelenggara sampai pihak keamanan). Sebagai contoh algoritma tatalaksana henti jantung saat ini bisa berpedoman pada AHA (American Heart Association), akses di lapangan bisa berpedoman pada hasil konsensus EACPR (European Association of Cardiovascular Prevention and Rehabilitation). Salinan 
akhir dari perencanaan kegawatdaruratan berupa diagram sderhana, berisi langkah pengaktifan sistem pelayanan kegawatdaruratan (termasuk di dalamnya menghubungi rumah sakit rujukan dan memanggil ambulans), instruksi RJP, penggunaan AED, dan rute serta akses masuknya ambulans (Wilson \& Drezner, 2016).

\section{Pelatihan}

Pelatihan ditujukan untuk petugas kesehatan dengan tujuan meningkatkan kemampuan dan ketrampilan dalam tatalaksana henti jantung. Pelatihan yang diberikan dapat berupa BHD (bantuan hidup dasar) dan BHL (bantuan hidup lanjut). Pelatihan minimal adalah berupa BHD yang diwajibkan untuk semua petugas kesehatan yang terlibat dalam suatu event olahraga. Pelatihan BHL dapat diberikan jika terdapat kesepakatan dengan penyelenggara event. Hal ini terkait dengan ketersediaan peralatan dan level event (Herring, Seattle, Kibler, dan Putukian, 2013). Sebagai contoh pada event PON semua petugas kesehatan wajib mengikuti pelatihan BHD dan minimal satu orang sebagai leader mengikuti pelatihan BHL (Kemenkes, 2010). Sedangkan Olimpiade mewajibkan semua dokter event mengikuti pelatihan BHL (McDonagh \& Zideman, 2015).

\section{Personel}

Tatalaksana henti jantung yang baik bisa diberikan jika jumlah petugas kesehatannya cukup, sehingga perbandingan jumlah petugas kesehatan dengan kapasitas suatu event harus sesuai dengan rasio yang ditetapkan. Jumlah minimal petugas kesehatan sudah direkomendasikan oleh EACPR untuk event dengan kapasitas total lebih dari 1000 orang. Dengan kapasitas total atlet, penonton dan ofisial diatas 10.000 orang pelayanan kesehatan suatu event olahraga harus memiliki minimal satu orang dokter, satu orang perawat dan dua orang teknikal medis (Börjesson et al., 2011). 
Tabel 1. Rekomendasi minimal personel pelayanan kesehatan pada event olahraga

\begin{tabular}{cccccc}
\hline Kapasitas Arena & AED & Dokter & Perawat & Teknikal Medis & Ambulans \\
\hline$<10.000$ & $1-2$ & 1 & 1 & 2 & $0-1$ \\
$10-50.000$ & 4 & 2 & $1-5$ & $2-10$ & $1-2$ \\
$>50.000$ & 8 & $2-4$ & $>5$ & $>10$ & $>2$ \\
\hline
\end{tabular}

\section{Peralatan}

Manajemen medis yang baik harus memastikan peralatan dasar untuk pelayanan kegawatdaruratan tersedia dan terpelihara, aksesnya mudah, dan dilabel dengan baik. Jenis peralatan yang disediakan juga berbeda berdasarkan jenis event dan tingkat keterampilan petugas kesehatan yang ada, minimal harus memiliki perlengkapan untuk bantuan hidup dasar (Cronin, Jordan, Quigley, \& Molloy, 2013; Dvorak et al., 2013).

Syarat-syarat perlengkapan dasar dalam kegawatdaruratan jantung harus memenuhi kriteria berikut:

1. AED disertai satu set PAD/bantalan AED yang terlabel tidak kedaluwarsa dan perlengkapan tambahan AED;

2. Ketersediaan alat bantu napas yang mudah digunakan minimal masker untuk bantuan pernapasan dari mulut ke mulut;

3. Alat pelindung diri berupa sarung tangan dan antiseptik tangan

4. Kartu instruksi RJP yang memiliki informasi yang mudah dimengerti tentang RJP yang efektif, cara aktivasi pelayanan kegawatdaruratan dan nomor telepon darurat; serta

5. Tempat penyimpanan peralatan kegawatdaruratan. Diharapkan bebas dari debu, tahan air, dan berukuran yang sesuai agar dapat membawa semua peralatan.

Kelengkapan tambahan yang juga dapat disiapkan jika memungkinkan antara lain oropharing airway (OPA), masker, bag-valve-mask (BVM) dan manualnya, perlengkapan imobilisasi spinal, monitor EKG minimal tiga lead (termasuk juga monitor tekanan darah, saturasi oksigen 
dan saturasi karbondioksida), peralatan bantuan nafas lanjut, akses vena sentral dan vena tepi, obat darurat intravena (McDonagh \& Zideman, 2015).

\section{Komunikasi}

Aktivasi dan koordinasi dari perencanaan kegawatdaruratan, transfer dan transportasi atlet yang mengalami henti jantung membutuhkan komunikasi yang efisien dan efektif di semua tingkat. Jika terjadi henti jantung di lapangan permainan, satu orang petugas kesehatan yang mengenali kejadian harus dapat menginformasikan kepada petugas lain sehingga pelayanan kegawatdaruratan dapat diaktifkan. Bentuk komunikasinya harus praktis dan spesifik sesuai lokasi. Jika tempat event kecil, informasi dapat disampaikan secara lisan. Jika tempat event sangat besar dan dibatasi oleh jarak, informasi dapat disampaikan melalui radio (Wilson \& Drezner, 2016).

\section{Transportasi}

Semua atlet yang mengalami henti jantung, baik yang masih diberi RJP maupun yang telah kembali ke sirkulasi spontan, wajib dipindahkan ke fasilitas terdekat yang lebih lengkap. Perlu dicatat bahwa protokol RJP Out-of-Hospital Cardiac Arrest (OHCA) secara internasional melarang transfer pasien henti jantung ke fasilitas kesehatan jika tidak ada sirkulasi spontan dari pasien. Tetapi untuk henti jantung pada atlet mendapat pengecualian, karena pada atlet yang mendapat pertolongan harus seminimal mungkin terpajan dengan penonton, media, ofisial dan atlet lain. Sehingga setelah tiga siklus sejak dimulainya RJP, atlet harus dipindahkan dari lapangan (Toresdahl et al., 2012).

\section{Persiapan akhir}

Pada persiapan akhir petugas kesehatan yang bertanggung jawab memastikan personel yang terlibat sudah memenuhi kualifikasi, peralatan yang disediakan sesuai dengan standar yang ada, nomor telepon layanan kesehatan rujukan benar. Serta menilai kembali area pertandingan, apakah area untuk evakuasi sudah sesuai dengan permintaan awal dan tidak ada gangguan 
yang mungkin menghalangi jalur evakuasi

(McDonagh \& Zideman, 2015).

\section{Algoritma tatalaksana henti jantung di lapangan permainan}

Elemen rantai keselamatan dalam tatalaksana henti jantung seperti mengenali gejala segera, resusitasi jantung paru segera (RJP), dan defibrilasi awal (bila terdapat indikasi) penting diingat oleh petugas kesehatan. Langkah-langkah sederhana ini penting diingat dan segera dimulai dalam beberapa detik setelah kejadian henti jantung. Petugas kesehatan harus sampai di lapangan permainan tidak lebih dari satu menit, RJP dimulai tidak lebih dari dua menit dan kardioversi diberikan tidak lebih dari tiga menit dari permulaan kejadian. Algoritma yang diberikan dalam tatalaksana dapat berupa BHD atau BHL, penting diingat perbedaan mendasar algoritma di lapangan permainan setelah tiga siklus RJP korban harus dipindahkan dari lapangan permainan (McDonagh \& Zideman, 2015).

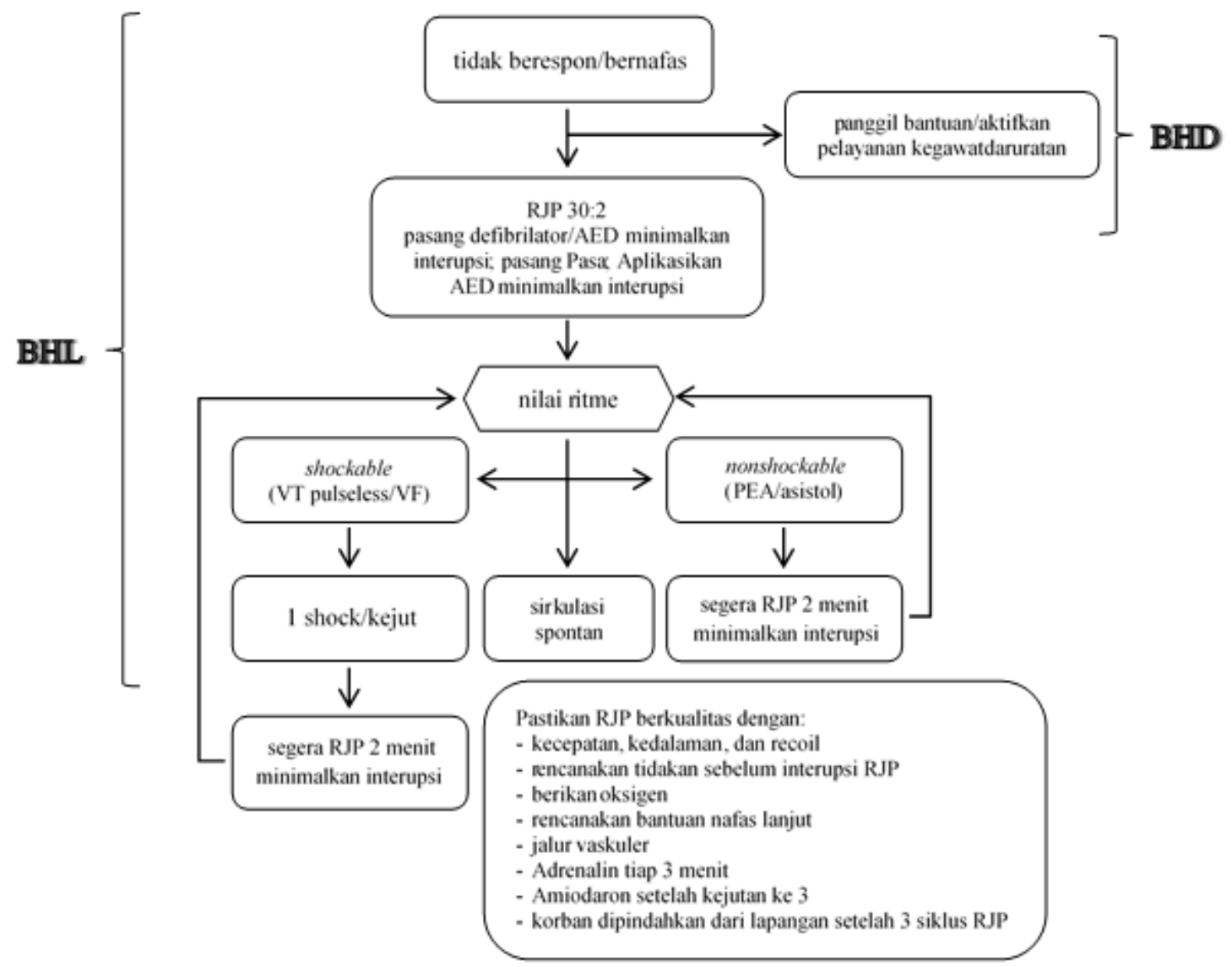

Gambar 1. Algoritma tatalaksana henti jantung di lapangan permainan 


\section{Bantuan hidup dasar}

Perlunya penilaian dengan cepat dan RJP segera merupakan kunci kesuksesan dari sebuah resusitasi. Petugas kesehatan perlu membuat penilaian pada atlet dengan pendekatan cek respon korban, membuka jalan nafas dan cek pernafasan serta memulai segera kompresi dada. Jangan menyela atau minimalkan interupsi selama kompresi dada, kecuali saat analisa irama jantung, saat memberikan kejutan dan memberi nafas buatan (bila tidak ada alat bantu nafas).

Satu-satunya cara untuk mempertahankan sirkulasi di lapangan adalah dengan kompresi dada. RJP yang berkualitas tergantung dari efisiennya kompresi dada dan minimalnya interupsi selama kompresi. Sehingga menjadi poin yang sangat penting dalam algoritma BHD untuk memberikan kompresi dada yang berkualitas dan memenuhi standar. Selama kompresi dilakukan harus tetap dilakukan pemantauan kualitas kompresi, bisa dilakukan dengan alat bantuan seperti monitor, audiovisual feedback atau kapnograf (Hazinski et al., 2015; Tanaka, Rodrigues, Sotir, Sagisaka, \& Tanaka; 2017).

\section{Penggunaan AED}

Penggunaan AED termasuk dalam algoritma bantuan hidup dasar, yang berfungsi untuk menganalisa irama jantung serta menghasilkan kejutan listrik. Setelah AED sampai, AED langsung dinyalakan dan kompresi dihentikan sementara untuk mengaplikasikan AED pada korban. AED akan segera menganalisis irama jantung korban. Hasil analisa dari AED adalah berupa anjuran pemberian kejutan (shockable rhytms) dan melanjutkan kompresi (nonshockable rhytms) (Cronin et al., 2013; Dvorak et al., 2013).

\section{Bantuan hidup lanjut}

Ketika bantuan hidup dasar telah dilaksanakan, bantuan hidup lanjut dapat dipertimbangkan. Bantuan hidup lanjut dapat dilakukan jika tersedia personel yang kompeten dan peralatan yang lengkap. Beberapa hal yang perlu dilanjutkan pada bantuan hidup lanjut yang tidak terdapat 
pada bantuan hidup dasar adalah pemberian alat bantu napas lanjut, akses vena, pemberian obat-obatan dan perawatan setelah resusitasi (Hazinski et al., 2015; McDonagh \& Zideman, 2015).

\section{Alat bantuan napas lanjut}

Selama RJP berlangsung, penolong dapat mempertimbangkan penggunaan alat bantuan napas lanjut. Karena jika bantuan napas selama resusitasi hanya menggunakan masker dan BVM, maka besar kemungkinan bantuan napas yang diberikan tidak adekuat. Alat bantuan nafas yang paling direkomendasikan adalah intubasi dengan tabung endotrakeal, namun teknik ini membutuhkan tenaga kesehatan yang sangat terlatih. Jika tenaga kesehatan yang ada tidak memiliki keterampilan untuk intubasi, tetap ada pilihan lain untuk alat bantu napas dengan penggunaan lebih mudah seperti laryngeal mask airway (LMAA) atau combitube (McDonagh \& Zideman, 2015).

\begin{abstract}
Akses Vena
Memasang akses vena perifer bertujuan agar obat dapat diberikan setelah defibrilasi awal. Pemberian obat lewat endotrakeal tidak lagi disarankan. Akses vena bisa langsung ke pembuluh darah perifer, atau setelah dua kali gagal mencoba intravena (IV) bisa dicoba melalui rute intraosseous (IO) (McDonagh \& Zideman, 2015).
\end{abstract}

\section{Obat-obatan}

Saat ini obat-obatan yang direkomendasikan pada bantuan hidup lanjut adalah epinefrin, amiodaron dan lidokain. Epinefrin diberikan jika irama jantung asistol atau PEA (Pulseles electric activity). Amiodaron atau lidokain diberikan jika irama jantung fibrilasi ventikel (VF). Semua obat yang diberikan melalui jalur intravena (Hazinski et al., 2015).

\section{Evaluasi pasca kejadian henti jantung}

Evaluasi terhadap para penolong yang terlibat harus dilakukan. Yang perlu dievaluasi antara lain apakah prosedur sudah sesuai, apakah ada kesalahan dalam 
penanganan, dan evaluasi keadaan psikis tenaga kesehatan dan penolong lainnya apakah mereka sampai membutuhkan bantuan psikolog. Tujuannya adalah agar terus ada peningkatan dalam pelayanan kegawatdaruratan jantung, dan perbaikan perencanaan dalam alur kegawatdaruratan tersebut (Wilson \& Drezner, 2016).

\section{KESIMPULAN}

Kejadian kematian akibat henti jantung pada atlet tergolong jarang, tetapi merupakan penyebab terbanyak kematian di lapangan permainan. PPE merupakan upaya preventif primer dari kejadian henti jantung di lapangan permainan, dengan PPE yang sesuai standar antisispasi terhadap atlet yang mempunyai risiko untuk henti jantung di lapangan dapat dilakukan lebih baik.

Upaya untuk mencegah kematian akibat henti jantung di lapangan permainan adalah dengan melakukan tatalaksana henti jantung secara cepat, benar dan efisien sehingga diperlukan manajemen medis sebelum event dimulai. Manajemen medis bertujuan agar alur kegawatdaruratan jantung dapat berjalan baik, mulai dari perencanaan kegawatdaruratan, mempersiapkan personel dan peralatan, mengatur sistem komunikasi, sampai mempersiapkan transportasi.

Tatalaksana henti jantung terdiri dari bantuan hidup dasar dan bantuan hidup lanjut. Penggunaan dan pemilihan tatalaksan tergantung kepada kompetensi personel, ketersediaan alat dan kese-pakatan dengan penyelenggara event. Tatalaksana yang benar dan cepat sejak dimulainya kejadian henti jantung akan meningkatkan angka bertahan hidup pada korban henti jantung tersebut.

\section{DAFTAR PUSTAKA}

Börjesson, M., Serratosa, L., Carre, F., Corrado, D., Drezner, J., Dugmore, D.L., ... Pelliccia, A. (2011). Consensus document regarding cardiovascular safety at sports arenas. European Heart Journal, 23(17), 2119-2124. http://doi.org.10.1093/eurheartj/ehr 178

Cronin, O., Jordan, J., Quigley, F., \& Molloy, M.G. (2013). Prepared for sudden cardiac arrest: a cross- 
sectional study of automated external defibrillators in amateur sports. British Journal of Sports Medicine, 47(18), 1171-4. http://doi.org/101136/bjsports2013-092919

Dvorak, J., Kramer, E.B., Schmied, C.M., Drezner, J.A., Zideman, D., Patricios, J., ... Mandelbaum, B. (2013). The FIFA medical emergency bag and FIFA 11 steps to prevent sudden cardiac death: setting a global standard and promoting consistent football field emergency care. British Journal of Sports Medicine, 47(18), 1199202.

http://doi.org/10.1136/bjsports2013-092767

Harmon, K.G., Asif, I.M., Maleszemski, J.J., Owens, D.S., Prutkin, J.M., Salerno, J.C., ... Drezner, J.A. (2015). Incidence, etiologu, and comparative frequency of sudden cardiac death in national collegiate athletic association athletes a decade in review. AHA Journal, 132(1), 10-19. http://doi.org/ 10.1161/CIRCULATIONAHA. 115 015431

Harmon, K.G., Drezner, J.A., Wilson, M.G., \& Sharma, S. (2014). Incidence of sudden cardiac death in athletes: a state of the art review. British Journal of Sports Medicine, 48, 1185-1192. http://doi.org/10.1136/bjsports2014-093872

Hazinski, M.F., Shuster, M., Donnino, M.W., Travers, A.H., Ricardo, Samson, A., ... Sinz, E.H. (2015). Highlights of the 2015 American Heart Association guidelines update for CPR and ECG.Texas: American Heart Association.

Herring, S.A., Seattle, C., Kibler, W.B., \& Putukian, M. (2013). Team physician consensus statement. ACSM, 45(8), 1618-1622. http://doi.org/101249/MSS.0b013e 31829 ba437

Kemenkes. (2010). Pedoman penyelenggaraan event olahraga bidang kesehatan. Jakarta: Dirjen Binkenmas.

McDonagh, D., \& Zideman, D. (2015). The IOC manual of emergency sports medicine. Oxford: Wiley Blackwell.

Tanaka, S., Rodrigues, W., Sotir, S., Sagisaka, R., Tanaka, H. (2017). $C P R$ performance in the presence of audiovisual feedback or football shoulder pads. BMJ Open Sports Exerc Med, 1-10. http://doi.org/ 10.1136/bmjsem-2016-000208

Toresdahl, B., Courson, R., Börjesson, M., Sharma, S., \& Drezner, J. (2012). Emergency cardiac care in the athletic setting: from schools to the Olympics. British Journal of Sports Medicine, 46(Suppl 1), i85-i89. http://doi.org/101136/bjsports2012-091447

Wafsy, M.M., \& Hutter, A. (2016). Sudden cardiac death in athletes. Debakey Journal, 12(mar 18 19), 76-80. http://doi.org/10.1136/bmj.h1218

Wilson, M.G., \& Drezner, J.A. (2016). IOC manual of sports cardiology. Oxford: Willey Blackwell. http://doi.org/10.1002/9781119046 899 